\title{
Study on the formal beauty of plants in interior design
}

\author{
Juan Dong \\ Zhengzhou university of industrial technology, Zhengzhou451150, China.
}

2913602941@qq.com

Keywords: indoor plants, aesthetic value, formal beauty

\begin{abstract}
. with the improving of the living environment for people demands, a lot of living space, office space, commercial space owner will choose to use plants to add vigor of the interior space, adjust the atmosphere of interior space. When choosing plants, we are faced with a variety of plants to choose, how to match becomes a difficult problem. The formal beauty has found a reference model for us to choose plants and plants, and also provided some theoretical basis for interior designers to match plants in interior space. Busy work, tired life is full of urbanites every day, a small plant, can bring a touch of spiritual comfort when we are tired. In the face of diverse and colorful plants, how to match in the interior space becomes the problem that we encounter when designing, the formal beauty provides the theory basis for this question.
\end{abstract}

\section{The connotation of indoor plant form beauty}

Formal beauty refers to the aesthetic characteristics of the natural properties and the combination of the physical materials that constitute things. Formal beauty of form factor in general can be divided into two parts: the first part is a form of perceptual material, the second part is a combination between perceptual material law of formal beauty, or the form law and aesthetic principles. The first part refers to the colors, patterns, branches, fruits and roots of the indoor plants themselves, which show their own state in different seasons and environments. The second part refers to the formal beauty of the same kind and different plants according to certain laws and rules. The first and second parts, in the form of the United States and China, are both independent and mutually influential.

\section{Content of formal beauty}

The content of formal beauty is the external and internal embodiment of the form, such as: the straight line represents the calm, the curve shows the movement; Red denotes caution and enthusiasm, green denotes environmental protection and tranquility, white denotes cleanliness and purity; The triangle represents stability and the square indicates the dun-thick. These different lines, different colors, and different shapes reflect the meaning of formal beauty. Formal beauty is an independent aesthetic object, and its significance is universal. In primitive society, the leaves and skins were made into clothes according to certain rules, and the bones and teeth of hunting animals were strung together to make ornaments. When these articles bring people pleasure, the psychological feeling that produces is the form aesthetic feeling. The form aesthetic feeling is closely related to the human physiology and psychology, from the practical function to the spiritual function transformation, this is the formal beauty from nothing to the generation process. In this process, people summed up some rules, such as the law of the change and unity, symmetry and the laws of equilibrium, rhythm and the rule of the law of rhythm, harmony and contrast, etc, these laws are continuously grope in production activities, human.

\section{Characteristics of indoor plant form beauty}

\section{1 features of formal beauty}

Aesthetic characteristics refers to the naturalproperty constitutes a material things (colour, shape, 
line, etc) and combination rules (jagged and qi, balance and symmetry, etc) presented by the aesthetic features. When we buy indoor plants, we are usually attracted by their natural properties. Fragrance overflowing, for example, tangy smell, beautiful, delicate and charming flowers, graceful branches, the color of leaves, bare root, such as the nature of the indoor plants in the design is very good. But when it comes to different plants, there are many problems. The perceptual material combination rule of formal beauty, namely the law of formal beauty, provides the theoretical basis for us.

\section{2 elements that form the beauty of indoor plant form}

\subsection{1 colour}

In indoor plants, we can understand the color as the basic elements of indoor plants, such as the inherent color, accessories and scenery of plants. These colors are either single or rich, directly stimulate the visual organ of the human,give people different visual feelings and psychological feelings, and the use of different colors directly affects the whole indoor environment. In addition, we also consider part of the plant, as the light, moisture and temperature in different seasons is different, color changes, to this kind of plant accessories, entourage of, want to consider more comprehensive. For example, in winter, the rainbow jade is often green, and in spring, summer and autumn, as the intensity of light increases, the whole plant becomes red. When considering a scene, you should take into account the different colors of the same plant at different times, which requires the designer to know about the plant's growth habit.

\subsection{2 form}

Indoor plants are based on different combinations of points, lines and surfaces. In interior design, plants do not exist alone, but are combined by these dots, lines, and surfaces. The points can be individually formed, the aggregation of points can be composed of lines, and the aggregation of lines can be formed. Point in space, plants use the separate place of plants in the interior space, here refers to the separate set of plant can be individual plant, may also be more plant in the same combination of potted plants, plant using point that plants in interior space with independent existence; The use of plant line that plants in interior space, arranged in linear combinations of plants, can be a straight line and curve line, the use of plant line that plants in interior space has outspread feeling; On the surface of the plant using different linear plants in interior space namely according to certain rules or optional put together, make plants form the effect in the whole space, plants use below that plants in interior space has surround close feeling. Different combinations of points, lines and faces, the forms and effects of plants are varied, and the formal beauty is different (figure 1, figure 2).

\section{Rules for the beauty of indoor plants}

The artistic quality of interior plant design requires us to follow certain aesthetic rules, namely the beauty law of form, and guide the design by applying the beauty law of form. In the book aesthetics, the philosopher Hegel once said, "the elements of beauty can be divided into two kinds, one is internal and the other is content. The other is external, that is, content lends itself to something that is meaningful and characteristic. The formal beauty law can make us from inside to outside all have the law to follow.

The constitution law of formal beauty mainly includes change and unification, symmetry and balance, rhythm and rhythm, harmony and contrast, etc. These laws are the characteristics of human beings who are constantly familiar with and master the various perceptual material factors in the activities of creating beauty, and abstract and generalize the connection between the form factors. 4 plant collocation of these constitute a rule for interior design provides a theoretical basis and guiding principle, the designer according to the formal beauty of form principle in indoor space collocation gives conform to the requirements of customers of different kinds of plants.

\section{1 the constitution law of change and unity}

Change reflects the difference of things; Unity embodies the interconnectedness of things. 
Changes in indoor plants are different in different forms, colors and plant types. Unity reflects the interconnectedness of various plants, the same color, the same plant type, the same smell, etc. emphasizing the wholeness of various plants. The change and unity reflect the characteristics of plants themselves and the characteristics of the plants, which is the embodiment of the principle of opposites and unity. In the design of indoor plants, plants have different colors, different collocation form in the interior space to present a general direction of the unification, small changes, unified with whole plant design, opposites that an plant design changes, changes in the whole sex is the window of the overall design, but at the same time, should pay attention to is in unity for the change. In the whole interior plant design, change should pay attention to the principle of "degree", cannot"invariant" also cannot "changeful".

\section{2 the constitution of symmetry and equilibrium}

Symmetry shows that things are separated from the central axis, and the size, size and shape of the body are identical. Equilibrium reflects the in a certain range, the size of the things, size, shape, for the center with visual impact the strongest local things keep visual sense on the vision of balanced, is not necessarily a symmetrical balance things. Symmetrically in the interior plant design the body now places the same size, the same variety of plants in the same space, the plant itself can be placed together, accord with the principle of symmetry; Plants can also be placed in a symmetrical form around the interior space, both of which accord with the principle of symmetry of indoor plants. Balanced in the interior plant design, the overall size, color and other visual elements of the plant are distributed, with the most visual impact of the center as the center, maintaining a balance in the vision. We should adopt the principle of symmetry in the design of indoor plants for solemn and formal places. Symmetry can reflect the sense of order, stability, solemnity and majesty. In the living space and the design feels stronger public space (such as bars, stores, office space, art galleries, etc.) can be based on the principle of balance, make the plant design center to avoid fully symmetrical state, has the certain model (figure 3, figure 4).

\section{3 the constitution of rhythm and rhythm}

Rhythm and rhythm originally came from music. The rhythm shows that music has regular repetition and change according to certain beats. The rhythm reflects the change in music process, which emphasizes an appeal, is a psychological feeling, and has a strong emotional color. Rhythm is in interior plant design to reflect the plant in space through different line, color, direction, modelling and so on the certain rule that shows. These laws can be equal to distance, color uniformity, color gradient, color form of the same distance jump, high and low, light and dark contrast, etc. For example, different varieties of plants interarrange to form a rhythm; Different high and low plant interaction arrangement forms the rhythm sense and so on.

\section{4 constitution of harmony and contrast}

Harmony emphasizes a kind of harmonious relationship between each element of things, emphasizing a feeling of gentle, comfortable and calm, and the pursuit of identity. Contrast emphasizes the opposition between things, different feelings, the pursuit of difference. Harmony in reflected in the design of indoor plant plant the principle of unity in the space, the collocation of color, same size, same shape, same make the plants in the indoor space presents a smooth state. Contrast in indoor plant design reflects the diversity of plants in space, different color is the color of collision, the differences between the different plant type plants, different changes in temperature the collocation of configuration and the actual situation relations, contrast is the use of interior space through the plant collocation collision sparks new design. On plant design, harmony and contrast can exist at the same time, but there is only one occupies the dominant position, the contrast and harmony reflects the contradiction of two states, contrast is pursuing differences in harmony and harmony is the difference in the pursuit of consistent (figure 5, figure 6).

\section{Summary}

Golgi once said, "formal beauty is a form that can affect emotion and reason, and this form is a power." Indoor plant design form and all form, follow the certain principle and the law of formal beauty of law mainly have change and unity, symmetry and balance, rhythm and rhythm, harmony 
and contrast, etc. At the same time also note form is changing the development of human society, the rule of all is both universal and sex of time and space, in a different country, culture, ethnic background, the formal beauty is in constant development of the indoor plants.

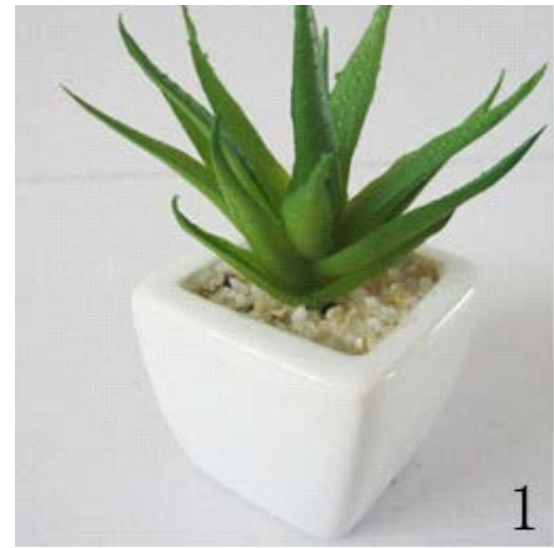

Figure 1. Points in interior space

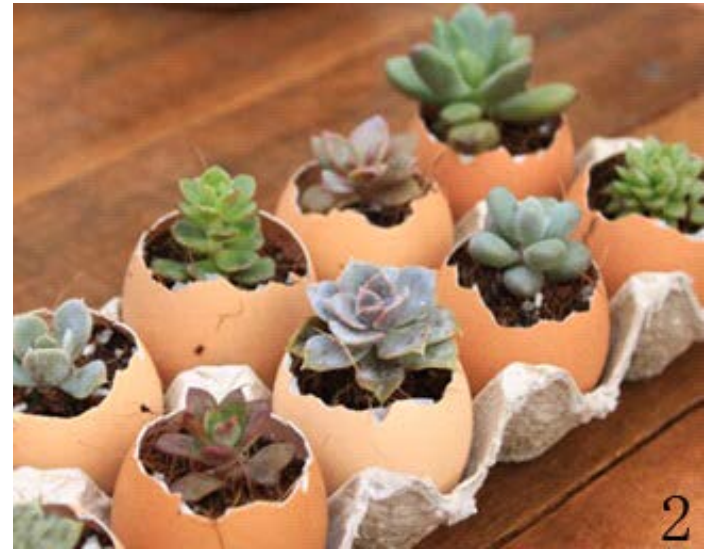

Figure 2. Surface in interior space

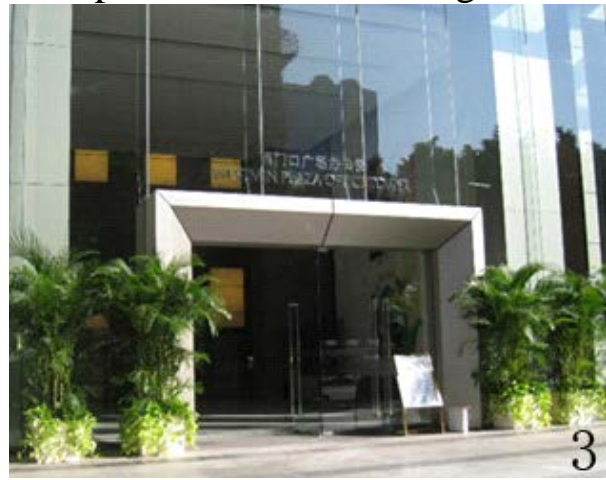

Figure 3. The symmetry principle of plants at the entrance of the hall

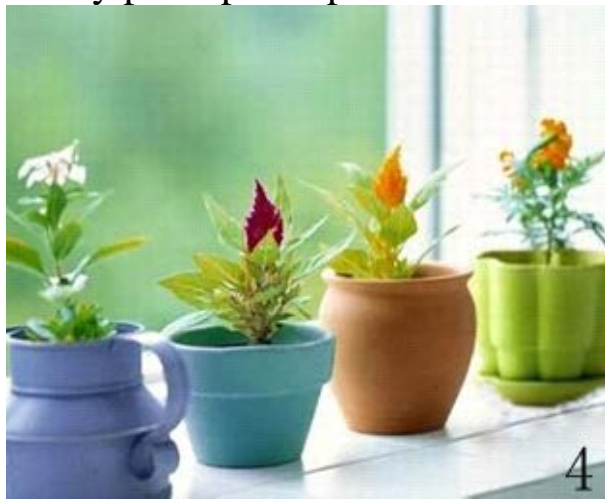

figure 4. Interior space is the equilibrium principle of plants

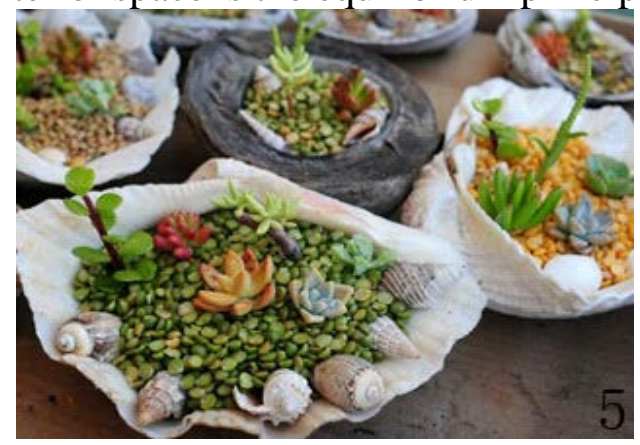

figure 5. Harmony and contrast of plants in interior space 


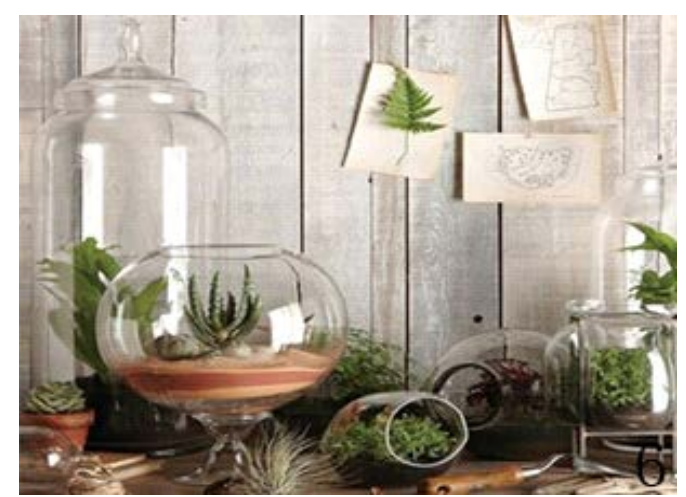

figure 6. Harmony and contrast of plants in indoor air Spaces

\section{References:}

[1] Jinghuan Zhao. Visual form aesthetics. sichuan fine arts publishing house, 2012, p. 58-62.

[2] Hegel. Aesthetics.commercial press, 1979, p. 128-132.

[3] Yuanping Wang. Interior design. China construction industry press, 2001,p. 115-120.

[4] Changxin Feng. Interior decoration design. China forestry publishing house, 2003, p. 72-75.

[5] Bo Jin. Indoor gardening. Beijing chemical publishing house, 2002 ,p. 158-162. 